\title{
Increased Polyamines May Downregulate Interleukin 2 Production in Rheumatoid Arthritis
}

\author{
Eliezer Flescher, Terry L. Bowlin, ${ }^{*}$ Ana Ballester, Richard Houk, ${ }^{\ddagger}$ and Norman Talal \\ Clinical Immunology Section, Audie L. Murphy Memorial Veterans Hospital and the Department of Medicine, The University of \\ Texas Health Science Center, San Antonio, Texas 78284-7874; *Merrell Dow Research Institute, Cincinnati, Ohio 45215; \\ and ${ }^{\ddagger}$ Wilford Hall United States Air Force Medical Center, San Antonio, Texas 78236
}

\section{Abstract}

Polyamines downregulate immune reactivity. $R A$ is associated with decreased IL 2 production. In this study, we present evidence to suggest that excessive polyamines can contribute to the IL 2 deficiency in RA. Blocking polyamine production with inhibitors of ornithine decarboxylase results in increased IL 2 production by RA PBMC. Moreover, polyamine oxidase (PAO) inhibitors and catalase also increase IL 2 production by RA PBMC. This effect of PAO inhibition is monocyte mediated.

After $3 \mathrm{~d}$ in culture, RA PBMC produce three times more IL 2 than do normal PBMC. This rise is prevented by exogenous spermidine but only in the presence of monocytes. The concentration of polyamines in RA PBMC and synovial fluid MNC is 2-20-fold higher than in normal cells.

Thus, polyamines and their oxidation products downregulate IL 2 production by RA PBMC and may account for the decreased $\mathrm{T}$ cell effector function seen in this disease.

\section{Introduction}

PHA-stimulated peripheral blood (PB) ${ }^{1}$ and synovial fluid (SF) lymphocytes from RA patients produce less IL 2 in comparison to normal PBL (1). A decreased PHA response follows in vitro infection with $E B V$ and can be corrected by removal of monocytes (2). The response to PHA can be partially restored by adding indomethacin, a prostaglandin biosynthesis inhibitor (3). The defect in PHA-stimulated IL 2 production seen in systemic lupus erythematosus can be reversed by resting the cells in culture for $2-3 \mathrm{~d}(4)$.

Ornithine decarboxylase (ODC) catalyzes the synthesis of putrescine from ornithine. Putrescine is metabolized into

Part of this work was reported in an abstract presented at the American Rheumatism Association in Houston, TX, 1988.

Address reprint requests to Dr. Norman Talal, Professor of Medicine and Microbiology, Head, Division of Clinical Immunology, The University of Texas Health Science Center, 7703 Floyd Curl Drive, San Antonio, TX 78284-7874.

Received for publication 2 June 1988 and in revised form 26 August 1988.

1. Abbreviations used in this paper: DFMO, difluoromethylornithine; MDC, monocyte-depleted cells; MDL, $N$-2,3-butadienyl derivative of putrescine (MDL 72,527 DA); MNC, mononuclear cells; $\alpha \mathrm{MO}, \alpha-$ methyl ornithine; ODC, ornithine decarboxylase; PAO, polyamine oxidase; PB, peripheral blood; SF, synovial fluid.

J. Clin. Invest.

(C) The American Society for Clinical Investigation, Inc.

$0021-9738 / 89 / 04 / 1356 / 07 \$ 2.00$

Volume 83, April 1989, 1356-1362 spermidine and spermine by the addition of one or two propylamine groups, respectively (5). Putrescine can be oxidized by diamine oxidase and the products are $\mathrm{H}_{2} \mathrm{O}_{2}$, ammonia, and $\gamma$-aminobutyr-aldehyde. Spermine and spermidine are also oxidized, by polyamine oxidase (PAO), to produce $\mathrm{H}_{2} \mathrm{O}_{2}$, ammonia, and different aldehydes (6).

IL 2 production by murine (7) and human (8) lymphocytes is increased when these cells are treated with $\alpha$-difluoro-methylornithine (DFMO), an ODC inhibitor. ODC inhibition decreased the polyamine content of the treated cells; the increased IL 2 production was reversed by the addition of polyamines. Polyamines also inhibit lymphocyte proliferation and other parameters of immunity (9). Bovine PAO acts on polyamines to generate immunosuppressive products (10). The inhibition of cell proliferation by exogenously added polyamines may be mediated by a PAO originating from a cellular source (11).

We have evidence that IL 2 production by normal PBL is downregulated by the products of spermidine oxidation (11a). We now report that immunosuppressive products related to polyamines and polyamine oxidase may play a role in the $T$ cell hyporesponse of RA patients.

\section{Methods}

Patients and blood donors. A total of 40 patients and 15 sex- and age-matched normal healthy donors were studied. All patients (34 females and 6 males) had active RA and fulfilled the American Rheumatism Association criteria for the diagnosis of RA. The subjects had a mean age of 54.4 yr (range 21-69). All patients were treated with nonsteroidal antiinflammatory drugs, five with methotrexate, nine with gold, four with D-penicillamine, four with imuran, three with corticosteroids, and one with cytoxan. No correlation was found between any of the phenomena described in this work and the medication of the RA patients.

$60-120 \mathrm{ml}$ of heparinized venous blood was taken from each subject. SF was drawn from RA patients with knee effusions. The SF specimens were incubated with $50 \mu \mathrm{g} / \mathrm{ml}$ hyaluronidase (Sigma Chemical Co., St. Louis, MO) and then handled like PB to purify various cell populations.

Cell separations. Mononuclear cells (MNC) from venous blood or SF were prepared by Ficoll-Hypaque (Pharmacia Fine Chemicals, Uppsala, Sweden) density gradient centrifugation. All cell preparations mentioned in Results and Discussion are RA PB cells unless otherwise stated.

T cells were prepared by first allowing MNC to adhere to plastic dishes at $37^{\circ} \mathrm{C}$ for $1 \mathrm{~h}$ and then taking the nonadherent cells and purifying from them cells capable of forming rosettes with sheep erythrocytes. Briefly, $3 \times 10^{7}$ nonadherent MNC in $3 \mathrm{ml}$ complete medium (see below) were mixed with $3 \mathrm{ml}$ of $5 \times 10^{8} / \mathrm{ml}$ suspension of neuroaminidase-treated sheep erythrocytes in medium and incubated at $37^{\circ} \mathrm{C}$ for $15 \mathrm{~min}$, then centrifuged (at $200 \mathrm{~g}$ for $5 \mathrm{~min}$ ) and further incubated at $4^{\circ} \mathrm{C}$ for $45 \mathrm{~min}$. Thereafter, the rosetted cells were obtained by centrifugation through Ficoll hypaque. The erythrocytes in 
the cell pellet were lysed by exposure to $0.83 \% \mathrm{NH}_{4} \mathrm{Cl}$ in $0.017 \mathrm{M}$ Tris-HCl buffer for $7 \mathrm{~min}$. The rosetted cells contained $>92 \%$ T3-positive cells as checked by flow cytometry.

OKT8-negative cells were prepared from total $T$ cells by a panning technique. Briefly, $20 \times 10^{6}$ cells $/ \mathrm{ml}$ were suspended in OKT 8 hybridoma supernatant (ATCC CRL 8014; American Type Culture Collection, Rockville, MD) and incubated for $45 \mathrm{~min}$ at $4^{\circ} \mathrm{C}$. Cells were washed, suspended in PBS + 5\% FCS and put into flasks, precoated with goat anti-mouse IgG, for $90 \mathrm{~min}$ at $4^{\circ} \mathrm{C}$. The last step was repeated and nonbound cells were collected. About $90 \%$ of the T cells with suppressor phenotype cells were removed by this technique as checked by flow cytometry.

The term monocyte-depleted cells (MDC), mentioned later on in the text, refers to either nonadherent $\mathrm{MNC}$ or $\mathrm{T}$ cells. Both these cell preparations contained 4-5\% monocytes (by flow cytometry) and produced the same amounts of IL 2.

Culture medium. All cell cultures were performed at $37^{\circ} \mathrm{C}, 5 \% \mathrm{CO}_{2}$ in RPMI 1640 medium supplemented with 10\% heat-inactivated FCS, $2 \mathrm{mM}$ L-glutamine, $25 \mathrm{mM}$ Hepes buffer, $100 \mathrm{U} / \mathrm{ml}$ penicillin, and 100 $\mu \mathrm{g} / \mathrm{ml}$ streptomycin. All the reagents were from Gibco Laboratories (Grand Island, NY) and this medium is referred to in the text as complete medium. HB101 (New England Nuclear, Boston, MA) was used as a serum-free medium.

Assay for IL 2 secretion. Cells were suspended at $2 \times 10^{6} / \mathrm{ml}$ and various reagents were added. Stimulation was always with $2 \mu \mathrm{g} / \mathrm{ml}$ PHA (Burroughs-Wellcome, Durham, NC). After 24 h, supernatants were harvested and stored at $4^{\circ} \mathrm{C}$ until they were assayed.

IL 2 activity was detected using a murine IL 2-dependent cytotoxic T cell line (CTLL-2). The assay was described in detail elsewhere (1). Results were calculated using probit analysis (12).

Cell proliferation assay. MNC were resuspended in complete medium at a concentration of $2 \times 10^{6} \mathrm{cell} / \mathrm{ml}$ and $100 \mu \mathrm{l}$ was placed in 96-well round-bottom plates (Costar Corp., Cambridge, MA). The cells were incubated with or without $2 \mu \mathrm{g} / \mathrm{ml} \mathrm{PHA}$. This concentration was found to be optimal. Cultures were incubated for $72 \mathrm{~h}$ and tritiated thymidine $\left({ }^{3} \mathrm{H} ; 1 \mu \mathrm{Ci} /\right.$ well in $10 \mu \mathrm{l}$, specific activity $\left.6.7 \mathrm{Ci} / \mathrm{mmol}\right)$ was added $6 \mathrm{~h}$ before termination of the culture. Cells were harvested on glass fiber filters by using a semiautomatic cell harvester (Mini-Mash 23-500; M. A. Bioproducts, Walkersville, MD). Cultures were performed in triplicate and the data were expressed as mean counts per minute. Radioactivity was measured in a liquid scintillation counter (Packard Instruments, Downers Grove, IL).

$O D C$ assay. $20 \times 10^{6} \mathrm{~T}$ cells were incubated for $24 \mathrm{~h}$ with or without PHA $(2 \mu \mathrm{g} / \mathrm{ml})$ and purified human IL $1(2.5 \mathrm{U} / \mathrm{ml}$; Cistron Technology, Palo Alto, CA). The assay was a modification of (13). The entire assay was done at $4^{\circ} \mathrm{C}$. Cells were harvested, pipetted into $3.5-\mathrm{ml}$ tubes, and spun at $400 \mathrm{~g}$ for $7 \mathrm{~min}$. Supernatants were aspirated off and $0.5 \mathrm{ml}$ of $50 \mathrm{mM} \mathrm{Na}_{2} \mathrm{HPO}_{4}$ (pH 7.2) containing $0.1 \mathrm{mM}$ EDTA, 20 mM DTT (Calbiochem-Behring Corp., La Jolla, CA), 5 mM NaF, 2 mM PMSF phosphate (Calbiochem-Behring Corp.) was added to each tube. Cells were sonicated for $20 \mathrm{~s}$ and then centrifuged at $10,000 \mathrm{~g}$ for $5 \mathrm{~min}$. Two aliquots of $180 \mathrm{ml}$ from each sample were incubated separately for $60 \mathrm{~min}$ with $20 \mu \mathrm{l}$ of $\mathrm{L}-\left[1-{ }^{14} \mathrm{C}\right]$ ornithine $(0.05 \mathrm{mCi} / 0.14$ mg per $0.5 \mathrm{ml}$ ) (New England Nuclear) in $15-\mathrm{ml}$ conical centrifuge tubes fitted with rubber stoppers and center wells (Kontes Co., Vineland, $\mathrm{NJ})$. The released ${ }^{14} \mathrm{CO}_{2}$ was collected by absorption to filter paper to which $20 \mu \mathrm{l}$ of $2 \mathrm{~N} \mathrm{NaOH}$ was added. The assay was terminated by adding $1 \mathrm{ml}$ of $1 \mathrm{M}$ citric acid. Absorbed radioactivity on the filters was counted by liquid scintillation spectroscopy.

Polyamine analysis. Samples of $3 \times 10^{6}$ fresh MNC were pelleted and frozen at $-20^{\circ} \mathrm{C}$ until they were assayed in triplicates. The preparation of the cells for reversed-phase HPLC and the subsequent polyamine analysis were done according to reference 14 .

Flow cytometry using immunofluorescent staining. Cells were washed two times and suspended in cold PBS containing 1\% FCS, and aliquots were put into $12 \times 75 \mathrm{~mm}$ polystyrene tubes at a total concentration of $1-2 \times 10^{6}$ cells/tube. Cell pellets were incubated for 20 min at $4^{\circ} \mathrm{C}$ with $100 \mu \mathrm{l}$ of the optimal dilution of fluorescein isothio- cyanate-conjugated MAb in $1 \%$ PBS-FCS. Cells were then washed once with $1 \mathrm{ml}$ cold PBS and fixed in 1\% paraformaldehyde in PBS and stored at $4^{\circ} \mathrm{C}$ until flow cytometry was performed. Flow cytometry was performed using a dual-laser FACS IV system (Becton Dickinson FACS Division, Sunnyvale, CA) to quantitate the stained cells.

Leu-4 and Leu-M3, Leu-2a, and Leu-3a (all from Becton Dickinson, Mountain View, CA) were used to identify human T cells, monocytes, and $\mathrm{T}$ cells with suppressor or helper phenotype, respectively.

Enzymes, IL 2, and chemicals. Quinacrine, a PAO inhibitor, catalase, $\alpha$-methyl ornithine ( $\alpha \mathrm{MO}$, an ODC inhibitor) spermidine, putrescine, 1,3-diaminopropane, cadaverine, hyaluronidase, asparagine, diamine oxidase, and monoamine oxidase were all from Sigma Chemical Co. Diphenhydramine hydrochloride (a PAO inhibitor) (Benadryl) was from Aldrich Chemical Co., Milwaukee, WI. Neuroaminidase was from ICN Biochemicals, Cleveland, $\mathrm{OH}$. Purified human delectinated IL 2 was from Cellular Products, Buffalo, NY. Difluoromethylornithine (an ODC inhibitor) and the N-2,3-butadienyl derivative of putrescine (a PAO inhibitor) (MDL 72, 527-DA) (MDL) were a gift from Merrell Dow Research Institute, Cincinnati, $\mathrm{OH}$.

Piroxicam (Feldene, an inhibitor of prostaglandins biosynthesis) was a gift from Pfizer Chemicals, New York, NY.

The monoamine oxidase used (EC 1.4.3.4) is assayed using the monoamine-benzylamine as a substrate. This amine oxidase from bovine plasma can oxidize spermidine as follows (6): spermidine $\stackrel{\mathrm{O}_{2}}{\rightarrow}$ $\mathrm{N}$-(4-aminobutyl)-3-aminopropionaldehyde + ammonia + hydrogen peroxide. It oxidizes polyamines at a 2.5 -fold higher rate than benzylamine and does not oxidize putrescine and cadaverine (15). Therefore, it was used as a PAO (16).

Statistical analysis of results. The statistical significance of the results was calculated using a one-tailed $t$ test.

\section{Results}

Regulation of IL 2 production by monocytes, prostaglandins, and hydrogen peroxide. Because $\mathrm{H}_{2} \mathrm{O}_{2}$ is produced by activated monocytes and macrophages and is also a product of PAO, we used catalase to assess the role $\mathrm{H}_{2} \mathrm{O}_{2}$ might play in the regulation of IL 2 production. As can be seen in Fig. 1, catalase increased IL 2 production by MNC, to a comparable degree as that affected by monocyte depletion, implicating $\mathrm{H}_{2} \mathrm{O}_{2}$ as an inhibitory signal. Neither inactivated catalase ( $20 \mathrm{~min}$ boiling, 1 min sonication) nor $1,300 \mathrm{U} / \mathrm{ml}$ SOD influenced IL 2 production. The addition of reagent $\mathrm{H}_{2} \mathrm{O}_{2}$ at 50,100 , and $200 \mu \mathrm{M}$ to MDC suppressed IL 2 production by 17,67 , and $88 \%$, respectively, without affecting cell viability by $>10 \%$ as assessed by the fluorescein diacetate assay. Prostaglandin synthesis inhibition increased IL 2 production in a dose-dependent fashion (Fig. 1).

Regulation of IL 2 production by polyamines. Because blocking ODC (a primary enzyme in polyamine biosynthesis) by its irreversible inhibitor DFMO increases IL 2 production by normal MNC, we investigated the effect of this drug on IL 2 production by RA MNC. We found that both DFMO and the reversible inhibitor $\alpha \mathrm{MO}$ have comparable enhancing effects on RA MNC (Table I). This effect appears to be mediated by reducing the concentration of the polyamine-spermidine and not the diamine-putrescine, as only spermidine counteracted the effect of $\alpha \mathrm{MO}$. $\alpha \mathrm{MO}$ acts in a dose-dependent way.

Products of polyamine oxidation can decrease IL 2 production. Having found that polyamines and $\mathrm{H}_{2} \mathrm{O}_{2}$ have an inhibitory effect on the capacity of human RA MNC to produce IL 2 , and in view of the information that products of enzymatic oxidation of polyamines have immunosuppressive properties (10), we tried to construct a model system in which the combi- 


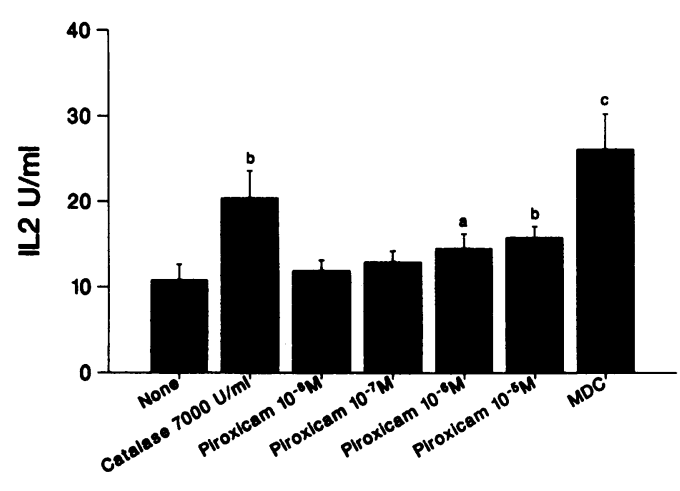

Figure 1. Effect of monocytes and their secretory products on IL 2 production. Fresh MNC or MDC were stimulated with PHA for $24 \mathrm{~h}$ in the presence of various agents. None, MNC with PHA only. Supernatants were harvested and assayed for IL 2 activity. The results are mean of three experiments \pm SD. The catalase concentration $(7,000 \mathrm{U} / \mathrm{ml})$ was found optimal. Catalase did not affect the CTLL-2 cells response to standard IL 2 . The significance of the differences between "none" and the other conditions is: $a, P<0.05 ; b, P<0.025$; c, $P<0.005$.

nation of PAO and polyamines will be essential and sufficient to downregulate IL 2 production by RA MNC.

These experiments were performed in serum-free medium with MDC because FCS contains PAO (9) and activated macrophages secrete PAO (17). PAO $\left(5 \times 10^{-4} \mathrm{U} / \mathrm{ml}\right)$ decreased IL 2 production significantly $(P<0.025)$ and this effect was abolished by catalase $(P<0.025)$ and $\alpha \mathrm{MO}$ that caused reduction in polyamine levels (Table II). Interestingly, the combination of PAO and spermidine did not suppress IL 2 production significantly more than PAO alone. This might be due to the lack of endogenous PAO (MDC in a serum-free medium) and limited supply of exogenous PAO.

The PAO effect depended upon substrate availability and thus, spermidine overcame the effect of $\alpha \mathrm{MO}(P<0.005)$. However, the PAO effect was abolished by catalase $(P<0.01)$

Table I. Effect of ODC Inhibitors on IL 2 Production

\begin{tabular}{lc}
\hline \multicolumn{1}{c}{ Condition } & $\begin{array}{c}\text { Percent enhancement } \\
\text { of IL 2 production }\end{array}$ \\
\hline None & $100 \pm 10.7^{*}$ \\
DFMO $(5 \mathrm{mM})$ & $132 \pm 11.6^{*}$ \\
$\alpha \mathrm{MO}(5 \mathrm{mM})$ & $134 \pm 4.9^{\ddagger}$ \\
$\alpha \mathrm{MO}(50 \mathrm{mM})$ & $221 \pm 25.6^{\ddagger}$ \\
$\alpha \mathrm{MO}(50 \mathrm{mM})+$ Spermidine $(10 \mu M)$ & $95 \pm 12.4^{\S}$ \\
$\alpha \mathrm{MO}(50 \mathrm{mM})+$ Putrescine $(10 \mu M)$ & $192 \pm 23.2^{\ddagger}$ \\
\hline
\end{tabular}

Fresh MNC were stimulated for $24 \mathrm{~h}$ by PHA in the presence of various reagents. Supernatants were harvested and assayed for IL 2 activity. The values in the Table are percentages of "none" $=12.1 \pm 1.3$ IL $2 \mathrm{U} / \mathrm{ml}$. The results shown are means of three experiments \pm SD. The samples were dialyzed before they could be assayed because DFMO has an inhibitory effect on the CTLL cells used for the IL 2 assay. The dialysis did not affect the IL 2 assay significantly. The addition of spermidine did not cause any loss of cell viability as assessed by the fluorescein diacetate assay ( $<5 \%$ dead cells). * Significance of difference in relation to "none," $P<0.025$. ‡ Significance of difference in relation to "none," $P<0.005$. ${ }^{8}$ Significance of difference in relation to $50 \mathrm{mM} \alpha \mathrm{MO}, P<0.005$.
Table II. The Combination of Spermidine and PAO Downregulates IL 2 Production

\begin{tabular}{ccccc}
\hline PAO & Catalase & $\alpha$ MO & Spermidine & IL 2 \\
\hline & & & & $U / m l$ \\
- & - & - & - & $29.1 \pm 3.2$ \\
+ & - & - & - & $21.4 \pm 2.4$ \\
+ & - & - & + & $19.6 \pm 2.5$ \\
+ & + & - & - & $28.6 \pm 3.5$ \\
+ & - & + & - & $30.3 \pm 3.6$ \\
+ & - & + & + & $18.2 \pm 2.1$ \\
- & - & + & + & $29.8 \pm 3.1$ \\
+ & + & + & + & $26.3 \pm 2.8$ \\
\hline
\end{tabular}

Fresh MDC were stimulated for $24 \mathrm{~h}$ by PHA in a serum-free medium (HB101) in the presence of various reagents. Supernatants were harvested and assayed for IL 2 activity. The data presented represent mean values of three experiments.

Neither the PAO nor the spermidine effects were due to nonspecific cytotoxicity as assessed by trypan-blue exclusion as well as the fluorescein diacetate assay $(<2 \%$ dead cells).

PAO, $5 \times 10^{-4} \mathrm{U} / \mathrm{ml}$; catalase, $7,000 \mathrm{U} / \mathrm{ml} ; \alpha \mathrm{MO}, 50 \mathrm{mM}$; spermidine, $10 \mu \mathrm{M}$.

even in the presence of $\alpha \mathrm{MO}$ and spermidine. The PAO effect was also abolished by the specific PAO inhibitor MDL (data not shown).

In conclusion, combination of PAO and a polyamine caused an $\mathrm{H}_{2} \mathrm{O}_{2}$ dependent inhibition of IL 2 production, whereas spermidine by itself or PAO in the absence of polyamines could not downregulate IL 2 production.

$P A O$ inhibitors increase IL 2 production. Having shown that exogenously added PAO can inhibit IL 2 production, we tested the effect of PAO inhibitors on IL 2 production in an attempt to find whether there is endogenous PAO in our cultures. As can be seen in Table III, the PAO inhibitor MDL (18) enhanced IL 2 production. Two other PAO inhibitors: $10^{-6} \mathrm{M}$ quinacrine (19) and $10^{-7} \mathrm{M}$ benadryl (20) also increased IL 2 production by MNC in 10\% FCS-containing medium by $42.2 \pm 4.3$ and $18.9 \pm 1.6 \%$, respectively. MDL is particularly important because it is a specific irreversible inhibitor of PAO

Table III. Effect of MDL on IL 2 Production

\begin{tabular}{cccc}
\hline MNC & MDC & FCS (10\%) & Increase in IL 2 production* \\
\hline & & $\%$ \\
+ & & - & $72.2 \pm 8.5^{\ddagger}$ \\
& + & + & $0.8 \pm 1.0$ \\
& + & & $25.3 \pm 2.3^{\S}$
\end{tabular}

Fresh MNC or MDC were placed in HB101 $10 \%$ FCS in the presence of $10^{-6} \mathrm{M} \mathrm{MDL}$ and PHA for $24 \mathrm{~h}$. Supernatants were harvested and assayed for IL 2 activity. The data presented is percent increase in IL 2 production over the same culture conditions without the PAO inhibitor. The values are means of three experiments $\pm S D$. The actual IL 2 levels produced by cells without drugs were: MNC, 17.2 $\pm 1.8 ; \mathrm{MDC}, 24.8 \pm 2.3 ; \mathrm{MDC}+\mathrm{FCS}, 21.4 \pm 1.9$.

* In relation to cultures lacking MDL.

* The significance of IL 2 production enhancement, $P<0.005$.

$\S$ The significance of IL 2 production enhancement, $P<0.05$. 


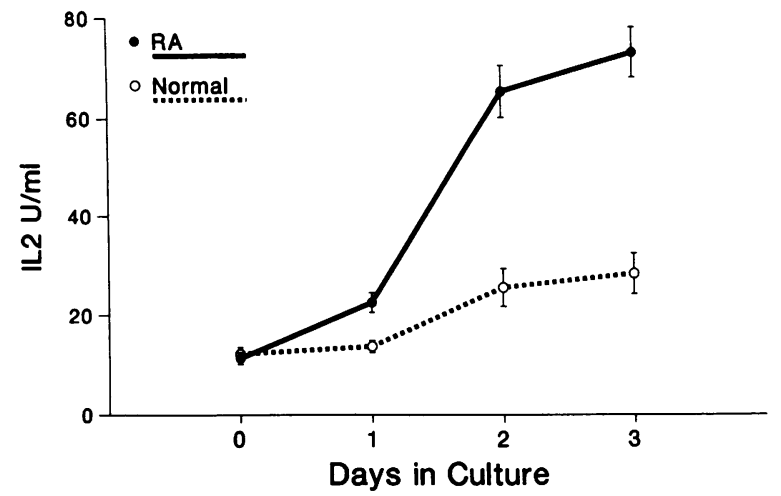

Figure 2. Effect of preincubation on IL 2 production. MNC were stimulated with PHA for $24 \mathrm{~h}$ either as fresh cells $(0 \mathrm{~d})$ or after 1-3 d of preincubation in complete medium. After the preincubation, cells were washed and recounted. After the PHA-stimulation period, supernatants were harvested and assayed for IL 2 activity. The results are means of 13 experiments $\pm S D$. When the production at days 1-3 was compared with that of fresh cells, $P$ was found to be $<0.0005$ in all cases (both normal and RA) with the exception of 1-d preincubation of normal cells, $P<0.05$.

(18). Table III also contains data suggesting that both FCS and monocytes were a source of PAO in our culture and, therefore, the IL 2 production of MDC grown in a serum-free medium was not affected by PAO inhibitors.

The concentrations of the drugs that were used were found the optimal ones, whereas higher concentrations were toxic (unpublished observations).

Preincubation in culture induces hyperproduction of IL 2 by $R A P B M C$. Normal PBMC produced two times more IL 2 than unrested cells after preincubation for $3 \mathrm{~d}$ in culture followed by exposure to PHA. However, RA PBMC produced six to seven times more IL 2 than fresh cells (Fig. 2). $3 \mathrm{~d}$ rest did not increase IL 2 production by SF MNC in three experiments (1.5 \pm 0.2 vs. $1.7 \pm 0.3 \mathrm{U} / \mathrm{ml})$. Comparison of normal and $\mathrm{RA}$ fresh and 3-d-rested PBMC failed to reveal any significant difference in the percentage of total $T$ cells, $T$ helper cells, and $\mathrm{T}$ suppressor cells as assayed by flow cytometry.

Spermidine specifically suppresses the IL 2 hyperproduction after 2 days of rest. Spermidine present during the preincubation period $(10 \mu \mathrm{M})$, reduced by $45 \%$ the amount of IL 2 produced by PHA-stimulated MNC (Fig. 3). This concentration of the polyamine was not cytotoxic as assessed by trypan blue exclusion. When spermidine was added to cells that have not been rested, it did not affect their PHA-induced IL 2 production indicating that the effect of this polyamine is time dependent. Three diamines were without effect. $10 \mathrm{mM}$ asparagine added to the preincubation culture inhibited IL 2 production by $29 \%$. This amino acid is known to induce ODC activity, which would bring about a rise in polyamine levels $(5,21)$.

Both FCS and monocytes were important for the spermidine effect. Withdrawal of both abolishes the inhibitory potential of spermidine (Fig. 4). Either serum withdrawal or monocyte depletion alone still allowed significant inhibition by spermidine $(P<0.01$ and $<0.025$, respectively).

Increased polyamine levels in $R A M C$. The regulatory effect of spermidine on IL 2 production suggested that a possible abnormality in polyamine synthesis might explain the IL 2

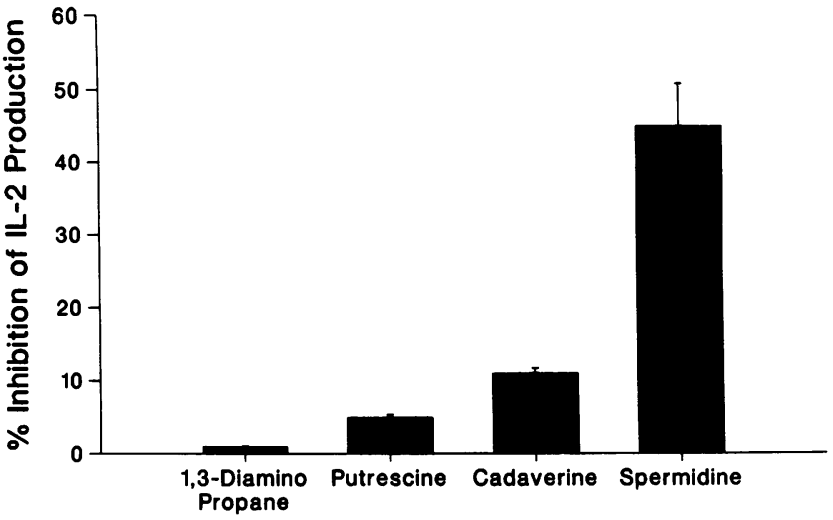

Figure 3. Effect of preincubation in the presence of polyamines on IL 2 production. MNC were incubated for $2 \mathrm{~d}$ in the presence of various polyamines $(10 \mu \mathrm{M})$ and then washed, recounted, and stimulated with PHA for $24 \mathrm{~h}$. Supernatants were harvested and assayed for IL 2. The results shown are percent inhibition of IL 2 production versus control cells incubated just in complete medium for $2 \mathrm{~d}$. The actual IL 2 level produced in these control cultures was 67.2 \pm 6.1 $\mathrm{U} / \mathrm{ml}$. The results shown are means of three experiments $\pm \mathrm{SD}$. The inhibition by spermidine was significant at $P<0.005$. The spermidine did not have a cytotoxic effect as assessed by the fluorescein diacetate assay $(<5 \%$ dead cells).

deficiency in RA. We measured polyamine levels in normal and RA MNC (Table IV) and found that putrescine, spermidine, and spermine were all significantly higher $(P<0.005$ and $<0.05$ ) in RA blood and SF cells, respectively, in comparison to normal cells. ODC activity in T cells from RA patients was very similar to that found in normal cells $(20.4 \pm 7.3$ vs. $22.2 \pm 6.1 \mathrm{pmol}{ }^{14} \mathrm{CO}_{2} / 160 \mathrm{~min}$ per $2 \times 10^{7} \mathrm{~T}$ lymphocytes, respectively) in four experiments.

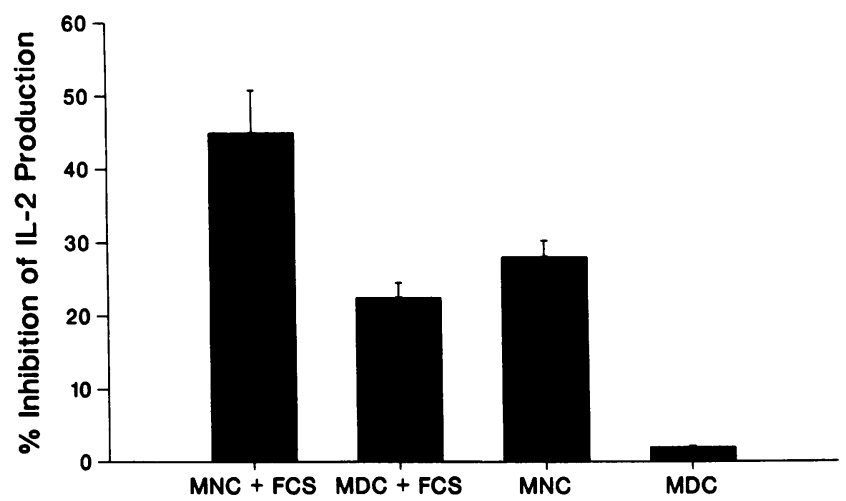

Figure 4. Serum and monocytes effects on IL 2 production by cells rested in the presence of spermidine. MNC or MDC were incubated for $2 \mathrm{~d}$ in $\mathrm{HB} 101 \pm \mathrm{FCS}(10 \%)$ in the presence of $10 \mu \mathrm{M}$ spermidine and then washed, recounted, and stimulated with PHA for $24 \mathrm{~h}$. Supernatants were harvested and assayed for IL 2 . The results shown are percent inhibition of IL 2 production versus control MNC incubated in HB101 + FCS for $2 \mathrm{~d}$. The IL 2 production by either MNC or MDC grown in HB101 $\mathrm{FCS}$ but without spermidine, was very similar ( $<5 \%$ difference). Therefore, the production by MNC in HB101 + FCS was used as the control for all the conditions. The actual control value was $63.2 \pm 6.2 \mathrm{U} / \mathrm{ml}$. The results shown are means of three experiments $\pm S D$. The spermidine did not have a cytotoxic effect as assessed by the fluorescein diacetate assay ( $<5 \%$ dead cells). 
Table IV. Polyamine Content of MNC from RA Patients Is Higher Than in Normal Cells

\begin{tabular}{lrcc}
\hline & Putrescine & Spermidine & Spermine \\
\hline Normals & $1.5 \pm 0.27$ & $69.1 \pm 10.7$ & $198 \pm 46$ \\
RA patients' blood & $12.2 \pm 2.12$ & $179.4 \pm 23.2$ & $462 \pm 56$ \\
RA patients' SF & $30.4 \pm 21.2$ & $224.0 \pm 92.1$ & $426.2 \pm 150.5$
\end{tabular}

Fresh MNC from peripheral blood and synovial fluid were washed three times and assayed for polyamine content. The values shown are pmol/liter $\times 10^{6} \mathrm{MNC} \pm \mathrm{SD}$. Five normal, five RA blood, and three RA SF samples were assayed.

IL 2 deficiency in RA cells is unrelated to OKT8 cells. T suppressor cells were found to contribute to the deficient IL 2 production by PB lymphocytes from SLE patients (22). We were not able to induce an increase in IL 2 production by RA $\mathrm{T}$ cells after the removal of $\mathrm{OKT} 8^{+}$cells by panning (Table V), in agreement with recent findings (23).

\section{Discussion}

IL 2 production by normal human PB lymphocytes is regulated by monocytes (24), PGE $(24,25)$, and polyamine levels (8). A monocytic cell line product inhibits IL 2 production (26).

Several autoimmune diseases $(1,27,28)$, including $\mathrm{RA}$, are characterized by hypoproduction of IL 2. Monocyte depletion enhanced IL 2 production by RA lymphocytes stimulated with EBV (2). Indomethacin, which blocks prostaglandin synthesis, also increased IL 2 production by RA cells (3). Both IL 1 (29) and IL 2 (30) inhibitors have been suggested as the cause of the low IL 2 production in RA.

We report another mechanism involved in the downregulation of IL 2 production in RA. PAO can oxidize polyamines and the products of this enzymatic reaction downregulate IL 2 production. The concentrations of polyamines in RA blood and synovial fluid MNC are increased 2-20-fold and monocytes are activated in RA synovial effusions. Thus, all the conditions are present in RA SF to generate immunosuppressive products based on a PAO-polyamine mechanism.

Monocytes from RA patients produce increased amounts of prostaglandin (31) and demonstrate enhanced hexose monophosphate shunt activity (32) and increased phagocytosis (33). Therefore, we investigated several possible mechanisms that monocytes might use to decrease IL 2 production. It was recently found that reagent $\mathrm{H}_{2} \mathrm{O}_{2}$ can suppress IL 2

Table V. Removal of $\mathrm{OKT}^{+}$Cells Does Not Affect IL 2 Production

\begin{tabular}{lrr}
\hline \multicolumn{1}{c}{ Source of cells } & Total T cells & OKT8 depleted \\
\hline Normal peripheral blood & $11.3 \pm 1.2$ & $12.5 \pm 1.7$ \\
RA peripheral blood & $9.8 \pm 1.3$ & $8.9 \pm 1.2$ \\
RA SF & $2.1 \pm 0.8$ & $1.9 \pm 0.6$
\end{tabular}

$\mathrm{T}$ cells and $\mathrm{OKT} 8^{-} \mathrm{T}$ cells were prepared as described in Methods. Cells were stimulated with PHA for $24 \mathrm{~h}$. Supernatants were harvested and assayed for IL 2 activity. Data shown is IL $2 \mathrm{U} / \mathrm{ml}$, means of three experiments $\pm \mathrm{SD}$. production by human lymphocytes (34) and so we decided to assess the possibility that endogenous production of $\mathrm{H}_{2} \mathrm{O}_{2}$ by human MNC regulates IL 2 production. We found that the $\mathrm{H}_{2} \mathrm{O}_{2}$ inhibitor, catalase, increased the measurable levels of IL 2 produced by $\mathrm{RA} \mathrm{MNC}$, indicating that $\mathrm{H}_{2} \mathrm{O}_{2}$ produced by the MNC might play a role in the regulation of IL 2 production. Furthermore, we have shown a dose-dependent inhibition of IL 2 production by $\mathrm{H}_{2} \mathrm{O}_{2}$ in the range of $50-200 \mu \mathrm{M}$ without a concomitant effect on cell viability. We also demonstrated that monocyte depletion enhanced IL 2 production by RA cells in a PHA-driven system.

The irreversible inhibitor of ODC-DFMO (35) and the reversible inhibitor $\alpha \mathrm{MO}$ were both potent enhancers of IL 2 production by RA cells. This effect was specifically inhibited by spermidine. The combined data that the polyamine-spermidine and $\mathrm{H}_{2} \mathrm{O}_{2}$ can both downregulate IL 2 production suggested that $\mathrm{PAO}$, by oxidizing polyamines and producing $\mathrm{H}_{2} \mathrm{O}_{2}$ (20), contributes to IL 2 suppression. PAO at low levels can be found in human serum and its level is elevated in serum from some hepatitis patients (17). Mouse-activated macrophages contain elevated levels of PAO and secrete it (17). Products of enzymatic oxidation of polyamines have immunosuppressive effects (10). We hypothesize that activated human monocytes also produce and secrete PAO that acts upon extracellular polyamines. The products of this enzymatic reaction downregulate IL 2 production by an as yet unknown mechanism. This regulatory effect is not necessarily restricted to RA cells and might function as a physiological way by which the immune response limits IL 2 production.

To test this hypothesis, we added PAO and spermidine to RA MDC in serum-free medium where ODC was blocked by $\alpha \mathrm{MO}$. We demonstrated that the combination of PAO and a polyamine is sufficient to downregulate IL 2 production and that this effect is catalase inhibitable. $\alpha \mathrm{MO}$, at $50 \mathrm{mM}$, was found to affect 9L cells through a mechanism that did not depend upon polyamine depletion because the addition of exogenous putrescine did not reverse the $\alpha \mathrm{MO}$ effect $(36,37)$. Although exogenous spermidine reversed the $\alpha \mathrm{MO}$ effect in our system (Table II), the possibility that $50 \mathrm{mM} \alpha \mathrm{MO}$ exerted an additional effect not dependent on ODC inhibition cannot be ruled out.

We present data (increased IL 2 production in the presence of PAO inhibitors) to suggest the presence of an endogenous PAO in our cultures. This occurred also in a serum-free medium suggesting that RA MC contain PAO activity. As no exogenous polyamines were added, their source had to be cellular. Mammalian cells produce and secrete polyamines during the natural course of their proliferation (38).

Elevated levels of $\mathrm{Ia}^{+}$(activated) $\mathrm{T}$ cells were found in the PB and much more profoundly in the SF of RA patients (39-42). In view of the IL 2 deficiency in RA, we hypothesize that the in vivo activation signal exhausts the $T$ cells so they appear activated by cell surface markers yet are weak functionally. A similar theory was proposed by Huang et al. (4) to explain the IL 2 deficiency in SLE. They found that T cells rested in culture for several days produced increased levels of IL 2. In this report we found that although SF MNC after rest still produced much less IL 2 than normal PB cells, MNC from RA blood produced greatly increased amounts of IL 2 (about three times more than normal blood cells) after rest. The production by normal cells was also elevated after rest as observed previously (4). Perhaps the SF T cells are too exhausted to be 
relieved by rest, whereas in RA blood, some in vivo suppressive effect may be abolished by rest. An in vivo priming effect is still functioning resulting in high levels of recovery.

We attempted to find whether this rise in IL 2 production after rest is polyamine inhibitable. We found that the polyamine spermidine but not three diamines significantly reduced the recovery and that this effect was both FCS and monocyte mediated. Because the cells were carefully washed after the rest period and before they were incubated for IL 2 production, it seems that the polyamine effect lasts even after the exogenously added polyamine is withdrawn.

Because we found that polyamines downregulate IL 2 production in RA MNC, we looked for an abnormality in polyamine metabolism of RA cells that might explain their IL 2 deficiency in comparison to normal cells. No difference in ODC levels was found but a significantly increased content of polyamines was measured in RA blood and SF MNC. Because mammalian cells secrete polyamines (38), these elevated levels could be a source of polyamines in the vicinity of RA MNC. (No difference between polyamines levels in the sera of normals and RA patients was found [43], yet the concentration near the activated cells secreting the polyamines might be the critical factor.) The levels of PAO produced and secreted by normal and RA cells are currently under investigation. It is interesting to note that blocking ODC with DFMO was recently reported to have beneficial effects in the treatment of murine lupus (44).

We suggest that RA cells use a polyamine-dependent mechanism to shut off the proliferation of $T$ cells by inhibiting IL 2 production. This might be a compensatory and protective mechanism designed to limit the $\mathrm{T}$ cell-driven destructive rheumatoid process. In this sense, the polyamine cascade would act in a manner similar to exogenous cyclosporin A which, although toxic, does have some efficacy in RA $(45,46)$.

\section{Acknowledgments}

We thank Ann Kirkland for her help in the preparation of the manuscript.

This work was supported by the Research Service of the Veterans Administration and by a grant from the CIBA-GEIGY Corporation. Eliezer Flescher is a postdoctoral fellow of the Chaim Weitzmann Fund.

\section{References}

1. Combe, B., R. M. Pope, M. Fischbach, B. Darnell, S. Baron, and N. Talal. 1985. Interleukin-2 in rheumatoid arthritis: production of and response to interleukin-2 in rheumatoid synovial fluid, synovial tissue and peripheral blood. Clin. Exp. Immunol. 59:520-528.

2. Lotz, M., C. D. Tsoukas, S. Fong, C. A. Dinarello, D. A. Carson, and J. H. Vaughan. 1986. Release of lymphokines after infection with Epstein Barr virus in vitro. II. A monocyte-dependent inhibitor of interleukin 1 down-regulates the production of interleukin 2 and interferon- $\gamma$ in rheumatoid arthritis. J. Immunol. 136:3643-3648.

3. Andary, M., B. Combe, J. Sany, and J. Clot. 1986. Interleukin-2 (IL-2) abnormalities in rheumatoid arthritis. Proc. 6th Int. Congress Immunol. 409. (Abstr.)

4. Huang, Y. P., P. A. Miescher, and R. H. Zubler. 1986. The interleukin 2 secretion defect in vitro in systemic lupus erythematosus is reversible in rested cultured T cells. J. Immunol. 137:3515-3520.

5. Canellakis, E. S., D. Viceps-Madore, D. A. Kyriskidis, and J. S. Heller. 1979. The regulation and function of ornithine decarboxylase and of the polyamines. Curr. Top. Cell. Reg. 15:155-202.
6. Tabor, H., and C. W. Tabor. 1972. Biosynthesis and metabolism of 1,4-diaminobutane, spermidine, spermine, and related amines. $A d v$. Enzymol. 36:203-268.

7. Bowlin, T. L., B. J. McKown, and P. S. Sunkara. 1987. The effect of $\alpha$-difluoromethylornthine an inhibitor of polyamine biosynthesis, on mitogen induced interleukin 2 production. Immunopharmacology. 13:143-147.

8. Bowlin, T. L., B. J. McKown, G. F. Babcock, and P. S. Sunkara. 1987. Intracellular polyamine biosynthesis is required for interleukin 2 responsiveness during lymphocyte mitogenesis. Cell. Immunol. 106:260-272.

9. Byrd, W. J., D. M. Jacbos, and M. S. Amoss. 1977. Synthetic polyamines added to cultures containing bovine sera reversibly inhibit in vitro parameters of immunity. Nature (Lond.). 267:621-623.

10. Labib, R. S., and T. B. Tomasi, Jr. 1981. Enzymatic oxidation of polyamines. Relationship to immunosuppressive properties. Eur. J. Immunol. 11:266-269.

11. Smith, C. J., R. Maschler, H. R. Maurer, and J. C. Allen. 1983. Inhibition of cells in culture by polyamines does not depend on the presence of ruminant serum. Cell Tissue Kinet. 16:269-276.

11a. Flescher, E., T. L. Bowlin, and N. Talal. 1989. Polyamine oxidation down-regulates interleukin-2 production by human peripheral blood mononuclear cells. J. Immunol. 142:907-912.

12. Gillis, S., M. M. Fern, W. Ou, and K. A. Smith. 1978. T cell growth factor parameters of production and a quantitative microassay for activity. J. Immunol. 120:2027-2032.

13. Fidelus, R. K., A. H. Laughter, and J. J. Twomey. 1984. The role of mitogens and lymphokines in the induction of ornithine decarboxylase (ODC) in T lymphocytes. J. Immunol. 132:1462-1465.

14. Bowlin, T. L., B. J. McKown, and P. S. Sunkara. 1986. Ornithine decarboxylase induction and polyamine biosynthesis are required for the growth of interleukin- 2 and interleukin- 3 dependent cell lines. Cell. Immunol. 98:341-350.

15. Mondovi, B., P. Turini, O. Befani, and S. Sabatini. 1983. Purification of bovine plasma amine oxidase. Methods Enzymol. 94:314318.

16. Allen, R. D., and T. K. Roberts. 1987 . Role of spermine in the cytotoxic effects of seminal plasma. Am. J. Reprod. Immunol. Microbiol. 13:4-8.

17. Morgan, D. M. L., J. Ferulga, and A. C. Allison. 1980. Polyamine oxidase and macrophage function. In Polyamines in Biomedical Research. J. M. Gaugas, editor. John Wiley \& Sons, New York. 303-308.

18. Berg, P., F. N. Bolkenius, N. Seiler, and P. Casana. 1985. $\mathrm{N}$-2,3-Butadienyl-1,4-butanediemine derivatives: potent irreversible inactivators of mammalian polyamine oxidase. J. Med. Chem. 28:1-2.

19. E. Holtta. 1977. Oxidation of spermidine and spermine in rat liver: purification and properties of polyamine oxidase. Biochemistry. 16:91-100.

20. Morgan, D. M. L. 1980. Polyamine oxidases. In Polyamines in Biomedical Research. J. M. Gaugas, editor. John Wiley \& Sons, New York. 285-302.

21. Kanamoto, R., S. M. Boyle, T. Oka, and S. I. Hayashi. 1987. Molecular mechanisms of the synergistic induction of ornithine decarboxylase by asparagine and glucagon in primary cultured hepatocytes. J. Biol. Chem. 262:14801-14805.

22. Linker-Israeli, M., A. C. Bakke, F. P. Quismorio, Jr., and D. A. Horwitz. 1985. Correction of interleukin-2 production in patients with systemic lupus erythematosus by removal of spontaneously activated suppressor cells. J. Immunol. 75:762-768.

23. Jahn, B., G. R. Burmester, P. Stock, P. Rohwer, and J. R. Kalden. 1987. Functional and phenotipical characterization of activated $T$ cells from intra-articular sites in inflammatory joint diseases. Scand. J. Immunol. 26:745-754.

24. Chouaib, S., and D. Fradelizi. 1982. The mechanism of inhibition of human IL2 production. J. Immunol. 129:2463-2473.

25. Rappaport, R. S., and G. R. Dodge. 1982. Prostaglandin E 
inhibits the production of human interleukin 2. J. Exp. Med. 155:943-948.

26. Krakauer, T. 1985. A macrophage-derived factor that inhibits the production and action of interleukin 2. J. Leukocyte Biol. 38:429_ 439 .

27. Linker-Israeli, M., A. C. Bakke, R. C. Kitridou, S. Gendler, S. Gillis, and D. A. Horwitz. 1983. Defective production of interleukin 1 and interleukin 2 in patients with systemic lupus erythematosus (SLE). J. Immunol. 130:2651-2655.

28. Miyasaka, N., N. Murota, K. Yamaoka, K. Sato, T. Yamada, T. Nishido, and M. Okuda. 1986. Interleukin 2 defect in the peripheral blood and the lung in patients with Sjogren's Syndrome. Clin. Exp. Immunol. 65:497-505.

29. Lotz, M., C. D. Tsoukas, C. A. Robinson, C. A. Dinarello, D. A. Carson, and J. H. Vaughan. 1986. Basis for defective responses of rheumatoid arthritis synovial fluid lymphocytes to anti-CD3(T3) antibodies. J. Clin. Invest. 78:713-721.

30. Miossec, P., T. Kashiwado, and M. Ziff. 1987. Inhibitor of interleukin-2 in rheumatoid synovial fluid. Arthritis Rheum. 30:121127.

31. Seitz, M., W. Deimann, N. Gram, W. Hunstein, and D. Gensa. 1982. Characterization of blood mononuclear cells of rheumatoid arthritis patients. 1. Depressed lymphocyte proliferation and enhanced prostanoid release from monocytes. Clin. Immunol. Immunopathol, 25:405-416.

32. Kay, N. E., and D. Douglas. 1979. Monocyte metabolic activity in patients with rheumatoid arthritis. Proc. Soc. Exp. Biol. Med. 161:303-306.

33. Hoch, S., and P. H. Schur. 1981. Monocyte receptor function in patients with rheumatoid arthritis. Arthritis Rheum. 24:1268-1277.

34. Staite, N. D., R. P. Messner, and D. C. Zoschke. 1987. Inhibition of human $T$ lymphocyte $E$ rosette formation by neutrophils and hydrogen peroxide. Differential sensitivity between helper and suppressor T lymphocytes. J. Immunol. 139:2424-2430.

35. Metcalf, B. W., P. Bey, C. Danzin, M. J. Jung, P. Casara, and J. P. Vevert. 1978. Catalytic irreversible inhibition of mammalian ornithine decarboxylase (E.C. 4.1.1.17) by substrate and product analogs. J. Am. Chem. Soc. 100:2551-2553.

36. Seidenfeld, J., and L. J. Marton. 1981. Considerations in the use of ornithine analogs. In Polyamines in Biology and Medicine.
D. R. Morris and L. J. Marton, editors. Marcel Dekker, Inc., New York. 311-314.

37. Seyfried, C., and D. R. Morris. 1983. Methods for the study of the physiological effects of inhibitors of polyamine biosynthesis in mitogen-activated lymphocytes. Methods Enzymol. 94:373-389.

38. Maurer, A., L. Melvin, and H. M. Keir. 1980. Excretion of polyamines from mammalian cells in culture. In Polyamines in Biomedical Research. J. M. Gaugas, editor. John Wiley \& Sons, New York. 363-388.

39. Burmester, G. R., C. T. Y. Yu, A. M. Irani, H. G. Kunkel, and R. J. Winchester. 1981. $\mathrm{Ia}^{+} \mathrm{T}$ cells in synovial fluid and tissues of patients with rheumatoid arthritis. Arthritis Rheum. 24:1370-1376.

40. Kluin-Nelemans, H. C., J. A. Vanderlinden, F. H. J. Gamelig Meyling, and H. G. Schuurman. 1984. HLA-DR positive T lymphocytes in blood and synovial fluid in rheumatoid arthritis. J. Rheumatol. 11:272-276.

41. Thoen, J., O. Forre, K. Waalen, and E. Kass. 1987. Phenotypes of $\mathrm{T}$ lymphocytes from peripheral blood and synovial fluid of patients with rheumatoid arthritis and juvenile rheumatoid arthritis. Scand. $J$. Rheumatol. 16:247-256.

42. Goto, M., T. Miyamoto, K. Nishioka, and S. Uchida. 1987. T cytotoxic and helper cells are markedly increased, and $\mathrm{T}$ suppressor and inducer cells are markedly decreased, in rheumatoid synovial fluids. Arthritis Rheum. 30:737-743.

43. Partsch, A., H. Desser, and G. Tausch. 1978. Die untersuchung der aliphatischen diamine und des histamins in serum von patienten mit chronischer polyarthritis. Z. Rheumatol. 37:329-334.

44. Thomas, T. J., and R. P. Messner. 1988. Beneficial effects of difluoromethylornithine (DFMO) on the life-span, lymphadenopathy, and anti-DNA autoantibody production of female MRL-1 pr/ $1 \mathrm{pr}$ mice. Arthritis Rheum: 31:S38. (Abstr.)

45. Dougados, M., and B. Amor. 1987. Cyclosporin A in rheumatoid arthritis: preliminary clinical results of an open trial. Arthritis Rheum. 30:83-87.

46. Forre, O., F. Bjerkhoel, C. F. Salvesen, K. J. Berg, H. E. Rugstad, G. Saelid, O. J. Mellbye, and E. Kass. 1987. An open, controlled, randomized comparison of cyclosporin and azathioprine in the treatment of rheumatoid arthritis: a preliminary report. Arthritis Rheum. 30:88-92. 